\title{
PERANCANGAN PERNIAGAAN DAN PRESTASI PERNIAGAAN: KAJIAN KE ATAS PKS ISLAM DI MALAYSIA
}

\author{
ROSLI MOHD SAAD \\ ABDULLAH ABDUL GHANI \\ SHUHYMEE AHMAD \\ College of Business \\ Universiti Utara Malaysia
}

\begin{abstract}
Abstrak
Aktiviti perancangan perniagaan telah terbukti berjaya mempengaruhi hubungan yang signifikan dengan prestasi perniagaan. Namun demikian, terdapat segelintir pengkaji yang melaporkan bahawa aktiviti perancangan perniagaan tidak penting. Hal yang demikian ini memberi kesan dan mempengaruhi ramai usahawan untuk tidak menyedia dan melaksanakan aktiviti ini dalam perniagaan. Rentetan itu, makalah meneliti kecenderungan usahawan mengaplikasikan aktiviti perancangan perniagaan dan hubungan aktiviti tersebut ke atas prestasi perniagaan. Kajian dijalankan menggunakan strategi kutipan data secara pos dan berdasarkan pensampelan kebarangkalian kelompok. Kajian ini melibatkan 117 sampel daripada sektor perkilangan/ pembuatan dan sektor pertanian dalam kalangan usahawan Perusahaan Kecil Sederhana (PKS) Islam di Malaysia. Penemuan kajian mendapati usahawan PKS Islam di Malaysia berkecenderungan mengaplikasikan aktiviti rancangan perniagaan dalam operasi perniagaan mereka. Selain itu, kajian juga mendapati perancangan perniagaan mempunyai hubungan yang signifikan positif dengan prestasi perniagaan.
\end{abstract}

Kata kunci: Perancangan perniagaan, prestasi perniagaan, perusahaan kecil dan sederhana.

\section{Abstract}

Purpose - Significant relationships have been reported between the variables of business planning and performance. However the effect of this relationship remains less important and studied empirically as it relates to the performance of Small and Medium Enterprises (SMEs) in Malaysia. Hence, this study is aimed to determine the significant effect of business planning on the relationship of SMEs' Muslims performance in Malaysia. 
Design - A quantitative research design based on the questionnaire survey was distributed and used to collect data. A total of 117 usable responses were received from the SMEs' Muslims from manufacturing and agriculture sectors in Malaysia

Findings - The findings reveal a significant and positive relationship between the variables of business planning and performance.

Significance - The study provides an important information as it suggests that the Muslims' SMEs should develop and implement business plan strategically in order to excel and remain competitive in the current challenging environment as well as to achieve better performance.

Keywords: Business planning, business performance, small and medium enterprises.

\section{Pengenalan}

Pencapaian prestasi Perusahaan Kecil Sederhana (PKS) di Malaysia masih lagi ditahap sederhana (Shuhymee, 2010). Hal ini dapat dilihat melalui sumbangan PKS terhadap Keluaran Dalam Negara Kasar (KDNK) negara secara perbandingan dengan PKS di negara-negara maju. Sumbangan PKS kepada KDNK di negara-negara maju seperti Jepun (53 \%), German (53\%), United Kingdom (51 \%), Korea Selatan (49\%) dan Singapura (49\%) menunjukkan pencapaian yang jauh lebih baik daripada PKS Malaysia. Di samping itu, PKS di Malaysia juga berdepan dengan pelbagai cabaran untuk bersaing dalam persekitaran dan ekonomi yang tidak menentu (Muhammad Hasmi, Norliza, Shahrudeen \& Sofri, 2004). PKS yang tidak mampu bersaing akan berprestasi rendah sementara PKS yang ingin terus bersaing perlu memiliki sumber-sumber dalaman perniagaan yang cemerlang bagi meningkatkan prestasi perniagaan (Barney, 1991; Dollinger, 2003). Sumber organisasi dan aktiviti perancangan perniagaan merupakan antara sumber-sumber penting yang mempengaruhi prestasi perniagaan (Dollinger, 2003). Oleh itu, PKS di Malaysia disyaratkan menyediakan perancangan perniagaan yang strategik untuk mendapatkan sumber modal perniagaan dan ianya merupakan sesuatu yang sukar dan menjadi cabaran kepada mereka (Muhammad Hasmi, Norliza, Shahrudeen \& Sofri, 2004). Namun demikian, terdapat juga kaijan-kajian lepas yang mendapati aktiviti perancangan perniagaan ini tidak penting dan tidak perlu disedia dan dilaksanakan. 
Seterusnya, bukti empirikal ke atas hubungan di antara aktiviti perancangan perniagaan dengan prestasi perniagaan didapati masih lagi tidak konsisten. Beberapa kajian lepas telah melaporkan terdapat hubungan yang signifikan di antara perancangan perniagaan dengan prestasi perniagaan (Gibson \& Cassar, 2002; Olsen, 2006; Veskaisri, 2007; Burke, Fraser \& Greene, 2010) dan terdapat juga beberapa kajian lain yang melaporkan tiada hubungan yang signifikan di antara perancangan perniagaan dengan prestasi perniagaan (Richardson, 2003; Mahdjoubi, 2004; Yusof \& Saffu, 2005). Walau bagaimanapun, kajian yang mengkaji hubungan antara perancangan perniagaan dan prestasi perniagaan ke atas PKS Islam di Malaysia belum lagi dilakukan. Sehubungan itu, kajian ini dijalankan untuk melihat adakah terdapat hubungan yang signifikan di antara perancangan perniagaan dan prestasi perniagaan PKS Islam di Malaysia?

Objektif kajian ini adalah untuk menentukan hubungan antara perancangan perniagaan dan prestasi perniagaan PKS Islam di Malaysia. Kajian Muhammad Hasmi et al. (2004) PKS di Malaysia telah membuktikan perancangan perniagaan mempengaruhi prestasi perniagaan. Namun demikian, mereka mencadangkan kajian selanjutnya keatas hubungan perancangan perniagaan dan prestasi perniagaan PKS di Malaysia perlu dilakukan di kawasan geografi dan sampel yang lebih besar untuk diperbandingkan. Menurut mereka lagi, kajian yang dijalankan oleh mereka adalah tidak menyeluruh dan meliputi kawasan Utara Semenanjung Malaysia (Perlis, Kedah, Pulau Pinang dan Perak) serta melibatkan 42 sampel firma PKS sahaja. Menurut Hair (1995), kajian menggunakan sampel dan kawasan geografi yang lebih besar berkemungkinan menghasilkan keputusan kajian yang berbeza (Sabitha, 2005).

Seterusnya, makalah membincangkan tentang literatur kajian pengkaji-pengkaji lepas dan pembentukan hipotesis kajian, metodologi kajian dan pengukuran pembolehubah-pembolehubah, seta melaporkan dan membincangkan penemuan kajian dan kesimpulan kajian.

\section{Sorotan Karya dan Pembentukan Hipotesis}

Menurut Donnely, Gibson dan Ivancevich (1998), perancangan adalah fungsian kepada pengurusan sesebuah organisasi atau firma dan merupakan aktiviti penting pengurusan yang menetapkan 
matlamat pada masa hadapan dan matlamat tersebut perlu dicapai. Perancangan, pengorganisasian, kepimpinan dan pengawalan merupakan empat fungsian utama pengurusan yang perlu diurus dengan baik (Donnely et al., 1998; Daft \& Marcic, 1998; Menurut Donnely et al. (1998) lagi, perancangan dikatakan antara fungsian pengurusan paling kritikal dalam menentukan sesuatu perniagaan itu dapat terus hidup. Oleh itu, perancangan ke atas perniagaan yang dijalankan tidak hanya penting kepada firma besar tetapi juga kepada firma PKS (Rue \& Ibrahim, 1998). Namun demikian, konsep perancangan bukan perkara atau idea baru yang hanya dipraktik oleh manusia sejagat. Amirul (2011) menjelaskan, konsep perancangan juga terdapat di dalam Al-Quran, iaitu Surah Ali Imran ayat 54 yang bermaksud:

ALLAH (SWT) berfirman dalam Al-Quran "Dan mereka merancang (tipu daya), Allah juga merancang (membalas tipu daya), dan ALLAH (SWT) adalah sebaik-baik perancang (membalas tipu daya)" (Surah Ali-Imran, ayat 54)

Selain itu, rancangan perniagaan juga merupakan satu proses dan terdiri daripada rancangan perniagaan formal dan tidak formal (Hannon \& Atherton, 1997). Rancangan perniagaan tidak formal adalah ringkas dan lebih menggambarkan idea awal perniagaan (Baringger, 2009). Rancangan perniagaan formal adalah menyeluruh dan mengandungi elemen-elemen bersesuaian dengan keperluan spesifik perniagaan (Baringger, 2009; Scarborough, 2012). Antara elemen atau komponen yang perlu berada dalam rancangan perniagaan formal ialah maklumat firma dan pengurusan, visi dan misi perniagaan, produk atau perkhidmatan, analisis pasaran dan firma pesaing, strategi pemasaran dan maklumat kewangan yang terperinci (Baringger, 2009). Rancangan perniagaan formal juga mengaplikasikan kaedah dan prosedur yang sistematik dan jelas (McKiernan \& Morris, 1994) serta mengambil kira tempoh jangkamasa perancangan (Rhyne, 1986).

Seterusnya, penemuan kajian Miller dan Cardinal (1994) melaporkan firma yang merancang menghasilkan keputusan prestasi perniagaan lebih baik daripada firma tidak merancang. Kajian oleh Boyd (1991) dan Castrogiovanni (1996) berkaitan kadar daya hidup (survival rate) firma perniagaan PKS pula mendapati firma yang melaksanakan rancangan perniagaan berprestasi lebih baik dan lebih tinggi kadar daya hidup berbanding firma yang tidak merancang perniagaan. 
Pengkaji lain seperti Muhammad Hasmi et al. (2004), Stewart (2003) dan Veskaisri (2007) turut membuktikan usahawan yang menulis dan melaksanakan rancangan perniagaan menunjukkan prestasi yang baik dan lebih berjaya berbanding dengan usahawan yang gagal berbuat demikian.

Walaupun ramai pengkaji telah membuktikan bahawa usahawan atau firma yang menulis dan melaksanakan rancangan perniagaan lebih berjaya tetapi terdapat juga pengkaji-pengkaji yang menemui sebaliknya tentang rancangan perniagaan. Mahdjoubi (2004) menjelaskan, rancangan perniagaan hanya digunakan sebagai alat komunikasi untuk berurusan mendapatkan sumber modal luar dan tidak perlu dijadikan sebagai panduan beroperasi kerana ia tidak memberi kesan kepada prestasi perniagaan. Gibson dan Cassar (2002) pula mendapati, rancangan perniagaan yang sofistikated hanya disediakan oleh firma-firma besar sahaja dan tidak perlu disediakan oleh firma kecil. Malah ada pengkaji yang berpendapat adalah lebih baik usahawan atau firma kecil memberi tumpuan kepada aktiviti yang lebih menguntungkan seperti strategi pemasaran dan kewangan (Corner, 2001) kerana boleh meningkatkan prestasi perniagaan.

Seterusnya, beberapa penemuan kajian lain turut menjelaskan bahawa rancangan perniagaan yang disediakan hanya membazirkan masa dan tidak banyak memberi manfaat kepada usahawan. Yusof dan Saffu (2005) menyatakan rancangan perniagaan tidak perlu dibuat dengan serius dalam keadaan ekonomi yang tidak menentu kerana firma-firma yang membuat rancangan perniagaan tidak menunjukkan peningkatan prestasi perniagaan. Terdapat PKS dan firma-firma perniagaan yang tidak membuat dan melaksanakan rancangan perniagaan kerana sumber-sumber yang terhad dan keadaan ekonomi yang berbahaya, dan menganggap penyediaan rancangan perniagaan sebagai aktiviti yang tidak perlu dilaksanakan (Bhide, 1994; Mathew \& Scott, 1995). Penemuan kajian-kajian ini menggambarkan kepentingan rancangan perniagaan adalah tidak konsisten. Selain itu, hubungan rancangan perniagaan ke atas prestasi perniagaan juga adalah pelbagai. Rentetan itu, kajian ini telah mencadangkan hipotesis berikut untuk di uji.

Hipotesis H1: Perancangan perniagaan berhubungan secara signifikan dengan prestasi perniagaan PKS Islam di Malaysia. 
IJMS 22, Special Issue 101-113 (2015)

\section{Metodologi Kajian}

\section{Sampel dan Kaedah Kutipan Data}

Sampel kajian ini melibatkan 117 usahawan PKS Islam di sektor perkilangan dan pertanian di Malaysia. Data primer dikutip menggunakan borang soal selidik berbentuk self-administered yang dilengkapkan. Teknik kutipan data diaplikasikan melalui pos kerana teknik ini terbukti membantu mendapatkan jumlah responden yang ramai dalam jangka masa yang pendek, mempunyai ciri-ciri kerahsiaan yang tinggi (Sabitha, 2005) dan menjimatkan serta efisen (Sany Sanuri, 2007). Selain itu, teknik ini juga memberi kelebihan kepada penyelidik dari perspektif logistik di mana ia lebih efisen untuk berurusan dengan responden yang ramai dan berada di lokasi yang jauh (Cavana, Delahaye \& Sekaran, 2001).

\section{Instrumen Kajian}

Instrumen kajian digunakan adalah berbentuk subjektif dan secara teknik lapor sendiri (self-report). Jumlah item dan skala yang digunakan bagi mengukur pemboleh ubah prestasi dan rancangan perniagaan adalah seperti tertera dalam Jadual 3.1.

Jadual 3.1

Instrumen Prestasi Perniagaan dan Rancangan Perniagaan

\begin{tabular}{llll}
\hline Pemboleh ubah & No. Item & \multicolumn{1}{c}{ Skala } & \multicolumn{1}{c}{ Sumber } \\
\hline Prestasi & 8 & 7 Skala Likert & $\begin{array}{l}\text { Azizi (2010) dan Shuhymee } \\
(2010)\end{array}$ \\
R. Perniagaan & 29 & 7 Skala Likert & $\begin{array}{l}\text { Richardson (1986) dan Stewart } \\
(2003)\end{array}$ \\
\hline
\end{tabular}

Pemboleh ubah rancangan perniagaan merangkumi aktiviti-aktiviti seperti misi ( 2 item), objektif ( 3 item), analisis luaran ( 3 item), analisis dalaman (2 item), strategi pilihan (4 item), pemilihan strategi (9), perlaksanaan strategi (3 item) dan kawalan (3 item) dan diukur menggunakan 7 Skala Likert. Nilai kebolehpercayaan Cronbach Alpha bagi pemboleh ubah prestasi perniagaan dan rancangan perniagaan masing-masing adalah 0.923 dan 0.952. Nilai ini baik dan boleh dipercayai seperti yang disarankan oleh Pallant (2007). 


\section{Penemuan dan Perbincangan}

Kajian ini melibatkan 117 responden, majoriti responden merupakan usahawan lelaki iaitu sebanyak 66 atau 56.4 peratus dan usahawan yang berusia 40 tahun ke bawah, iaitu sebanyak 74 atau 63.2 peratus. Selain itu, usahawan daripada sektor perkilangan didapati lebih ramai yang terlibat dengan kajian ini, iaitu sebanyak 82 atau 70.1 peratus berbanding sektor pertanian sebanyak 35 atau 29.9 peratus. Di samping itu, majoriti tahap firma usahawan yang terlibat berada pada peringkat pertumbuhan, iaitu sebanyak 59 atau 50.4 peratus.

Seterusnya, keputusan analisis deskriptif melaporkan pemboleh ubah prestasi perniagaan mempunyai nilai min 5.45 dengan skor minimum 4.00 dan skor maksimum 7.00. Hal ini menerangkan bahawa majoriti firma PKS Islam dalam kajian ini memiliki prestasi perniagaan yang tinggi. Sementara itu, keputusan analisis deskriptif ke atas pemboleh ubah perancangan perniagaan pula melaporkan nilai min, iaitu 5.49 dengan skor minimum 2.90 dan skor maksimum 6.72. Hal ini menerangkan bahawa majoriti usahawan PKS Islam di Malaysia sangat bersetuju dengan perlaksanaan aktiviti rancangan perniagaan dalam firma.

Sementara itu, keputusan analisis korelasi seperti di Jadual 4.1 menunjukkan aktiviti-aktiviti rancangan perniagaan telah berkolerasi secara signifikan antara satu sama lain dan bebas daripada kesan multikolineariti di mana nilai $\mathrm{r}$ yang signifikan tidak melebihi nilai 0.90 seperti yang disebut oleh Pallant (2010) dan Chua (2009). Pallant (2010) menjelaskan bahawa pemboleh ubah tidak bersandar mempunyai perbezaan yang nyata dalam hubungan antara satu sama lain dan boleh digunakan dalam analisis regresi.

Jadual 4.1

Analisis Korelasi antara Aktiviti Rancangan Perniagaan dan Prestasi Perniagaan

\begin{tabular}{|c|c|c|c|c|c|c|c|}
\hline & Prestasi & Misi & Obj & A.L & A.D & Strat & $\begin{array}{l}\text { Pemilih Perlaks } \\
\text { Kawal } \\
\end{array}$ \\
\hline Prestasi & 1.00 & & & & & & \\
\hline Misi & $.292^{* *}$ & 1.00 & & & & & \\
\hline Objektif & $.400^{* *}$ & $.643^{* *}$ & 1.00 & & & & \\
\hline A.Luaran & $.399^{* *}$ & $.512^{* *}$ & $.637^{* *}$ & 1.00 & & & \\
\hline
\end{tabular}


IJMS 22, Special Issue 101-113 (2015)

\begin{tabular}{|c|c|c|c|c|c|c|c|}
\hline & Prestasi & Misi & Obj & A.L & A.D & Strat & $\begin{array}{l}\text { Pemilih Perlaks } \\
\text { Kawal }\end{array}$ \\
\hline A.Dalaman & $.253^{* *}$ & $.599^{* *}$ & $.566^{* *}$ & $.641^{* *}$ & 1.00 & & \\
\hline Strategi & $.332^{* *}$ & $.526^{* *}$ & $.568^{* *}$ & $.701^{* *}$ & $.803^{* *}$ & 11.00 & \\
\hline Pemilihan & $.323^{* *}$ & $.685^{* *}$ & $.855^{* *}$ & $.667^{* *}$ & $.720^{* *}$ & $.645^{* *}$ & 1.00 \\
\hline Perlaksanaan & $.454^{* *}$ & $.494^{* *}$ & $.656^{* *}$ & $.607^{* *}$ & $.760^{* *}$ & $.655^{* *}$ & $.765^{* *} 1.00$ \\
\hline Kawalan & $.394^{* *}$ & $.611^{* *}$ & $.659^{* *}$ & $.709^{* *}$ & $.769^{* *}$ & $.781^{* *}$ & $.688^{* *} .667^{* *} 1.00$ \\
\hline
\end{tabular}

Selain itu, keputusan analisis regresi seperti Jadual 4.2 menunjukkan pemboleh ubah rancangan perniagaan juga didapati mempunyai hubungan positif yang besar dengan prestasi perniagaan $(\mathrm{r}=.413$, $\mathrm{p}<.01$ ). Nilai $\mathrm{R}^{2}$ sebanyak .171 menerangkan bahawa $17.1 \%$ perubahan yang berlaku dalam pemboleh ubah prestasi perniagaan adalah disebabkan oleh perubahan dalam pemboleh ubah rancangan perniagaan. Keputusan ujian ANOVA juga telah membuktikan terdapat hubungan yang signifikan antara pemboleh ubah tidak bersandar rancangan perniagaan dan pemboleh ubah bersandar prestasi perniagaan pada nilai $F(1,115)=23.689$, $p<.01$. Keputusan analisis regresi juga menjelaskan bahawa pemboleh ubah tidak bersandar rancangan perniagaan $(\beta=.413, \mathrm{p}<.01)$ telah berhubung secara signifikan positif dengan prestasi perniagaan dan merupakan faktor kepada PKS Islam untuk mencapai prestasi yang positif.

Penemuan ini telah membuktikan firma-firma PKS Islam di Malaysia yang membangun dan melaksanakan aktiviti rancangan perniagaan secara signifikan dapat mempengaruhi dan meningkatkan prestasi perniagaan. Beberapa aktiviti umum rancangan perniagaan seperti penyediaan kenyataan misi, mengenalpasti matlamat dan objektif firma serta membuat analisis persekitaran dalaman dan luaran dilihat sebagai aktiviti penting. Selain itu, aktiviti-aktiviti seperti penyediaan strategi-strategi pilihan, pemilihan strategi yang tepat dan perlaksanaan strategi dengan segera, penilaian dan pemerhatian yang berterusan ke atas proses perancangan perniagaan dilihat sebagai aktiviti penting yang perlu dilakukan oleh firma-firma PKS Islam.

Seterusnya, PKS Islam secara khusus perlu memberi perhatian kepada beberapa aktiviti lain seperti penglibatan sepenuhnya pihak pengurusan dalam menyediakan rancangan perniagaan strategik, memberi pertimbangan penting kepada pemilihan strategi 
jangka pendek dan jangka panjang, menyediakan belanjawan yang mencukupi, menyediakan prosedur formal untuk menilai dan melaksanakan perancangan perniagaan kerana aktiviti-aktiviti (itemitem rancangan perniagaan kajian) tersebut didapati menunjukkan nilai min yang tinggi dan berkecenderungan secara positif kepada peningkatan prestasi perniagaan.

Selain itu, PKS Islam di Malaysia juga perlu lebih yakin dengan kepentingan merancang. Ia bukan suatu idea baharu kerana Allah SWT sendiri merancang. Hujah mengatakan Allah SWT juga merancang adalah seperti yang dibincangkan oleh penyelidik dengan merujuk surah Ali-Imran ayat 54 dan konsep perancangan yang dibincangkan oleh Amirul (2011). Oleh itu, PKS Islam yang membuat perancangan adalah konsisten dengan keperluan dan kehendak Islam serta menepati ciri-ciri keusahawanan yang berjaya.

Seterusnya, penemuan kajian ini juga menyangkal dakwaan beberapa pengkaji terdahulu yang melihat dan mengkritik kepentingan rancangan perniagaan dari sudut ekonomi sebagai sesuatu yang membazir (Anantadjaya, 2007), disediakan hanya sebagai alat komunikasi untuk mendapatkan pinjaman (Mahdjoubi, 2004), tidak perlu disediakan secara serius dalam keadaan ekonomi yang tidak menentu (Yusof \& Saffu, 2005) dan hanya sesuai disediakan oleh firma-firma besar (Gibbon \& Cassar, 2002).

Selain itu, penemuan kajian ini juga dapat mengenepikan hujah yang memandang remeh kepada keperluan rancangan perniagaan dan mempertahankan tindakan serta syarat yang dikenakan oleh institusi perbankan kepada para usahawan PKS yang ingin mendapatkan pinjaman modal supaya terlebih dahulu menyediakan dokumen rancangan perniagaan. Sememangnya apa yang dilakukan oleh institusi perbankan ini bukan sahaja membantu mereka mengetahui secara mendalam tentang keperluan modal, kekuatan pengurusan, keseimbangan aset dan liabiliti, pemadanan sumber pembiayaan ekuiti dan hutang serta kecairan firma tetapi secara tidak langsung telah membantu firma-firma PKS merancang, mengorganisasi, memimpin dan mengawal kewangan projek atau perniagaan yang mereka jalankan dengan cekap dan berkesan. Hal ini demikian kerana semua elemen atau aktiviti terkandung dalam dokumen rancangan perniagaan yang strategik adalah berhubung kait dengan fungsian firma atau entiti sesuatu perniagaan. 
IJMS 22, Special Issue 101-113 (2015)

Jadual 4.2

Keputusan Analisis Regresi: Ringkasan model dan ANOVA

\begin{tabular}{ccccccc}
\hline $\begin{array}{c}\text { Model / } \\
\text { Pemboleh ubah }\end{array}$ & $\mathrm{R}$ & $\mathrm{R}^{2}$ & $\mathrm{R}^{2}$ Terlaras & $\begin{array}{c}\text { Ralat Piawai } \\
\text { nilai jangkaan }\end{array}$ & $\mathrm{F}$ & Sig. \\
\hline 1. R. Perniagaan & .413 & .171 & .164 & .76793 & 23.689 & .000 \\
\hline
\end{tabular}

Pemboleh ubah Bersandar: Prestasi Perniagaan

\section{Kesimpulan}

Kajian ini cuba untuk mendapatkan penjelasan tentang kepentingan pengurusan sumber-sumber dalaman seperti rancangan perniagaan ke atas prestasi perniagaan. Kajian ini mendapati pembolehubah tidak bersandar rancangan perniagaan telah mempengaruhi hubungan secara signifikan positif ke atas prestasi perniagaan. Kajian ini adalah konsisten dengan kajian oleh Veskaisri (2007) ke atas PKS di Thailand dan Muhammad Hasmi et al. (2004) ke atas PKS di Malaysia. Namun demikian, penemuan ini tidak konsisten dengan kajian oleh Richardson (1984), Mahdjoubi (2004) dan Oboreh dan Umokoro (2011). Walau bagaimanapun, penemuan kajian ini dari sudut metodologi telah dapat mengesahkan kajian sebelum ini oleh Muhammad Hasmi et al. (2004) yang menjalankan kajian yang sama dalam kawasan geografi dan sampel saiz yang lebih kecil.

Penemuan kajian ini dapat menambah khazanah penyelidikan serta dapat memberi pengetahuan tambahan kepada semua usahawan sama ada yang sedia ada atau pun yang baharu terutamanya kepada usahawan PKS Islam di Malaysia serta pihak-pihak yang berkepentingan dengan PKS supaya memberi fokus yang serius kepada penyediaan dan perlaksanaan rancangan perniagaan kerana terbukti mempengaruhi prestasi perniagaan. Sehubungan itu, kajian ini mencadangkan supaya kajian seumpama ini terus dikaji dengan menambah pembolehubah-pembolehubah sumber dalaman lain dan melibatkan usahawan PKS Islam daripada kategori mikro bagi mendapatkan gambaran yang lebih holistik serta memantapkan lagi kajian. 


\section{Rujukan}

Amirul Razali. (2011). Lipatan Sejadah. Allah sebaik-baik perancang. Dicapai daripada http://wahdahperkongsian.wordpress.com/ 2011/04/27/Allah-sebaik-baik-perancang/

Azizi Halipah. (2010). Pengaruh kompetensi keusahawanan, struktur organisasi dan persekitaran terhadap prestasi Perusahaan Kecil dan Sederhana di Malaysia (Thesis Phd tidak diterbitkan). Sintok: Universiti Utara Malaysia.

Barney, J. B. (1991). Firm resources and sustained competitive advantage. Journal of Management, 19, 99-120.

Barringer, B.R.(2009). Preparing effective business plan: Anentrepreneurial approach, (Pearson International Edition). Upper Saddle River: New Jersey.

Bhide, A. (1994). How entrepreneurs craft strategic that work. Harvard Business Review (March-April), 150-161.

Boyd, B. (1991). Strategic planning and financial performance: A metaanalytic review. Journal of Management Studies, 28(4), 353-274.

Burke, A. E, Fraser, S., \& Greene, F. J. (2010). Multiple effects of business plan on new ventures. Journal of Management Studies, 47(3).

Castrogiovianni, G. (1996). Pre-startup planning and the survival of new small businesses: Theoretical linkages. Journal of Management, 22, 801-822.

Cavana, R. Y., Delahaye, B. L., \& Sekaran, U. (2001). Applied business research: Qualitative and quantitative methods. Milton, Qld: Jon Wiley \& Sons Australia.

Chua, Y. P. (2009). Statistik penyelidikan lanjutan II: Ujian regresi, analisis factor dan analisis SEM. McGraw Hill Education.

Corner, P. (2001). Improving the performance of New Zealand's SME's. University of Auckland Business Reviews, 3(2), 51-56.

Daft, R. L., \& Marcic, D. (2006). Understanding management. Cengage Brain. com.

Dollinger, M. J. (2003). Entrepreneurship: Strategies and resources (3rd ed.). Upper Saddle River, New Jersey: Prentice Hall.

Donnelly, J. H., Gibson, J. L., \& Ivancevich, J. M. (1998). Fundamentals of management (10th ed.). Chicago: Richard D. Irwin.

Gibson, B. \& Cassar, G. (2002). Planning behaviour variables in small firms. Journal of Small Business Management, 40(3), 171-186.

Hannon, D. P., \& Atherton, A. (1997). Small firm success and the art of orienteering: The value of plans, planning, and strategic awareness in the competitive small firm. Journal of Small Business and Enterprise Development, 5(2), 102-109. 
Hair, J. (1995). Multivariate data analysis. New Jersey: Prentice Hall. Mahdjoubi, D. (2004). Knowledge, innovation and entrepreneurship. Business plans, capital, technology and growth of new ventures in Austin, Texas (Dissertation Paper Presented to the Faculty of the Graduate School of The University of Texas at Austin in August 2004).

Matthews, C., \& Scott, S. (1995). Uncertainty and planning in small and entrepreneurial firms: An empirical assessment. Journal of Small Business Management, 33(4), 34-52.

Mbengue, A. (2011). Strategic planning flexibility and firm performance: The moderating role of environmental dynamism. A conference paper: 1361. Miami: University of Reims.

McKiernan, P., \& Morris, C. (1994). Strategic planning and financial performance in UK SMEs: Does formality matter? British Journal of Management, 5, 31-41.

Miller, C. C., \& CardinalL. B., (1994). Strategic planning and firm performance: A Syntesis is more than two decades of research. Academy of Management Journal, 37(6), 1649-1665.

Muhammad Hasmi, Norliza, Shahrudeen \& Sofri. (2004). Business Performance of Small Medium Enterprise: Strategic Planning and Customer Focus. Conference of Information Technology and Organization in the $21^{\text {st }}$ Century, Challenges and Solutions, Jordan.

Oboreh, J. S., \& Umukoro, F. G. (2011). Determining the Impact of Environmental Characteristics and Uncertainty on the Strategic Plans of Corporate Organizations. Sacha Journal of Environmental Studies, 1(1), 31-40.

Olsen, E. (2006). Strategic planning for dummies. Wiley. com.

Pallant, J. (2007). SPSS survival manual: A step by step guide to data analysis using SPSS for windows (Version 15) (3rd ed.). Crows Nest, NSW: Allen \& Unwin.

Pallant, J. (2010). SPSS survival manual: A step by step guide to data analysis using SPSS. Open University Press.

Rue, L. W., \& Ibrahim, N. A. (1998). The relationship between planning sophistication and performance in small business. Journal of Small Business Management, 36(4), 24-32.

Rhyne, L. C. (1986). The relationship of strategic planning to financial performance. Strategic Management Journal, 7, 423-436.

Richardson, W. D. (1986). Investigation of strategic planning and financial performance ofselected U.S. businesses (Unpublished doctoral dissertation). Fayetteville: University of Arkansas.

Sabitha Marican, (2005). Kaedah penyelidikan sains sosial. Malaysia: Prentice Hall. 
Sany Sanuri Mohd Mokhtar. (2007). A relationship between market orientation and quality orientation and its impacts on the performance of Malaysia manufacturing firms (Tesis PhD tidak diterbitkan). Sintok: Universiti Utara Malaysia.

Scarborough, M. N. (2012). Effective small business management: An entrepreneurial approach. International edition (10th ed). New Jersey. Pearson Education.

Shuhymee Ahmad. (2010). Hubungan antara orientasi keusahawanan, gaya kepimpinan, dan persekitaran luaran dengan prestasi perniagaan: Satu kajian empirikal mengenai PKS di Malaysia. Perusahaan Kecil dan Sederhana di Malaysia (Tesis PHD tidak diterbitkan). Sintok: Universiti Utara Malaysia.

Stewart, K. S. (2003). The relationship between strategic planning and growth in small businesses (Unpublished DBA dissertation). USA: Nova Southeastern University.

Veskaisri, K. (2007). The relationship between strategic planning and growth in small and medium enterprises (SMEs) in Thailand. RU International Journal, 1(1), 55-67.

Yusof, A., \& Saffu, K. (2005). Planning and performance of small medium enterprise operators in a country in transition. Journal of Small Business Management, 43(4), 480-497. 